(6) OPEN ACCESS

\title{
Heated tobacco products likely appeal to adolescents and young adults
}

\author{
Karma McKelvey, ${ }^{1}$ Lucy Popova, ${ }^{2}$ Minji Kim, ${ }^{3}$ Benjamin W Chaffee, ${ }^{4}$ \\ Maya Vijayaraghavan, ${ }^{5}$ Pamela Ling, ${ }^{3}$ Bonnie Halpern-Felsher ${ }^{1}$
}

\begin{abstract}
- Additional material is published online only. To view please visit the journal online (http://dx.doi.org/10.1136/ tobaccocontrol-2018-054596).

${ }^{1}$ Division of Adolescent Medicine, Department of Pediatrics, Stanford University, Palo Alto, California, USA ${ }^{2}$ School of Public Health, Georgia State University, Atlanta, Georgia, USA ${ }^{3}$ Center for Tobacco Control Research and Education, University of California, San Francisco, California, USA ${ }^{4}$ Division of Oral Epidemiology and Dental Public Health, University of California, San Francisco, California, USA ${ }^{5}$ General Internal Medicine, Zuckerberg San Francisco General Hospital, University of California, San Francisco, California, USA
\end{abstract}

\section{Correspondence to} Dr Bonnie Halpern-Felsher Department of Pediatrics, Division of Adolescent Medicine, Stanford University, Palo Alto CA 94402, USA;

bonnieh@stanford.edu

Received 27 June 2018 Revised 13 September 2018 Accepted 17 September 2018

Check for updates

(C) Author(s) (or their employer(s)) 2018. Re-use permitted under CC BY-NC. No commercial re-use. See rights and permissions. Published by BMJ.

To cite: McKelvey $\mathrm{K}$,

Popova L, Kim M, et al.

Tob Control

2018;27:541-s47.

\section{ABSTRACT}

Background Beginning in the 1960s in the USA and globally since 1998, tobacco companies have beenaggressively promoting heated tobacco products (HTP). In 2016, Philip Morris International (PMI) applied to the US Food and Drug Administration (FDA) seeking authorisation to market their IQOS HTP system and flavoured 'HeatSticks' in the USA as a modified-risk tobacco product (MRTP).

Methods We systematically evaluated the publicly available data PMI submitted to FDA in its MRTP application to determine whether PMI's IQOS product meets the US Tobacco Control Act's standard for MRTP claims. We examined whether PMI provided sufficient data showing tobacco users will not initiate with IQOS, that youth will not misperceive the MRTP-related claims being made concerning IQOS, and how youth perceive health risks associated with IQOS.

Results PMI's own studies failed to provide evidence that youth, including non-users and former users, will not find IQOS appealing, will not initiate use of IQOS and will not perceive these products as risk-free. Further, PMI did not refer to independent studies conducted among adolescents which could influence their conclusions. Finally, their studies suffered from design and implementation flaws and cannot be relied on to support the proffered claims.

Conclusion PMI's own data and available evidence from scientific studies conducted independent of the tobacco industry regarding how novel tobacco products are currently being marketed suggest that introduction of IQOS will result in adolescent and young adult non-users initiating tobacco use with IQOS and could also increase poly-use of IQOS along with other tobacco products.

\section{INTRODUCTION}

Beginning in the 1960s in the USA and globally since 1998, tobacco companies have been developing heated tobacco products (HTP $)^{12}$; in 2017, tobacco companies began aggressive worldwide promotion of HTPs. In December 2016, Philip Morris International (PMI) submitted an application seeking the US Food and Drug Administration's (FDA) authorisation to market their IQOS HTP system and flavoured 'HeatSticks' in the USA as a modified-risk tobacco product (MRTP). In the application, PMI sought to make three claims in consumer marketing: (1) switching completely from cigarettes to the IQOS system can reduce the risks of tobacco-related diseases, (2) switching completely to IQOS presents less risk of harm than continuing to smoke cigarettes and (3) switching completely from cigarettes to the IQOS system significantly reduces your body's exposure to harmful and potentially harmful chemicals.

In accordance with the Family Smoking Prevention and Tobacco Control Act (Tobacco Control Act), ${ }^{3}$ when considering whether a new tobacco product such as HTPs should be introduced into the US market, the FDA must consider what impact the new products and its related marketing will have on adolescents (ages 10-17) and young adults (ages 18-25), including providing clear evidence about the effect the HTP and related marketing will have on adolescents and young adults (AYA) who are not using tobacco (including never and former tobacco users); whether the new product and related marketing will influence initiation; how AYA consumers actually use the HTP; evaluation of consumers' understanding and perceptions of the HTP, including its MRTP claims, labelling, marketing and advertising; and consumers' beliefs about the health risks of using the HTP relative to other tobacco products.

In this paper, we systematically evaluate the publicly available data that PMI submitted to the FDA in its MRTP application to determine whether PMI's IQOS meets the US Tobacco Control Act's standard for making their MRTP claims. In particular, we examine whether PMI provided sufficient data to show whether AYA who are not using tobacco (including never and former tobacco users) will initiate tobacco use with the new IQOS HTP product, whether HTP use among AYA consumers results in reduced levels of harm based on how they actually use the product, and whether AYA correctly understand the risks of HTP relative to other tobacco products. ${ }^{4}$

Because PMI studies provide no evidence on adolescents, we brought in evidence from other tobacco products, particularly e-cigarettes. Unlike regular combustible cigarettes, HTP heat sticks use an electronic heat source to create nicotine-containing aerosols to be inhaled by the user. The resemblance of the HTP device and process is similar to that of e-cigarettes which heat nicotine-containing liquids to generate aerosols. As such, HTPs are considered a form of e-cigarettes in Japan, ${ }^{5}$ Korea $^{1}$ and Italy. ${ }^{6}$ PMI, in their own studies on perceptions, used e-cigarettes for comparison with IQOS (and showed the products were rated similarly). ${ }^{4}$ These similarities in consumer perceptions are particularly important because the subjective perceptions and beliefs are what primarily drives consumer behaviour, rather than the physical product features, particularly among adolescents. 
Table 1 Systematic evaluation of evidence required by the Tobacco Control Act and evidence provided by PMI vs extant evidence to support or refute MRTP claims

\section{Evidence required by}

Tobacco Control Act

Will IQOS and its marketing increase the likelihood that
AYA non-users (including never users and former tobacco
products users) will start using the product?
products users) will start using the product?
PMI's evidence

PMI did not provide this evidence.

PMI claimed that in a premarket setting, the effect of IQOS on initiation among non-users could not be assessed. Instead, PMI used 'behavioural intentions' among adults as a proxy for behaviour.
Extant evidence as of 1 June 2018

Large proportions of non-users are using IQOS and other non-cigarette tobacco products. Studies have found evidence of gateway from e-cigarettes to combusted tobacco products.

Intentions are not a suitable proxy for actual behaviour, especially for adolescents. ${ }^{10-13} 48$ 55-57 7796

Epidemiological evidence suggests that for other noncigarette tobacco products, switching completely has not been the most common outcome. ${ }^{4877}$ in the PMI studies, PMI did not demonstrate that IQOS, as actually used by consumers, reduced levels of harm. of harm considering how consumers actually use IQOS, including concurrent use of multiple nicotine or tobacco products?

Does IQOS advertising or labelling enable the public to comprehend the information concerning modified risk in the context of total health and in relation to all of the diseases and health-related conditions associated with the use of tobacco products and cessation aids?
PMI's application did not include information from studies with adolescents younger than 18 . In PMI's studies, adult never-smokers had higher perceived risks of IQOS use compared with current or former smokers. They perceived risks of IQOS as lower than those of combusted cigarettes, but similar to health risks of e-cigarettes.
Extensive literature on adolescents conducted independently of the industry that PMI could have, but did not, present on current, former and non-users of cigarettes demonstrates the need to consider both perceptions of risks and benefits. ${ }^{15}$

The actual marketing of IQOS to date in countries other than the USA demonstrates that PMI has not adequately protected against use by non-smokers and suggests that the product's name, physical appearance, flavours and retail environment will appeal to young people. ${ }^{111314}$ $16-256897$

AYA, adolescents and young adults; MRTP, modified-risk tobacco product; PMI, Philip Morris International.

Finally, given that PMI's MRTP application and their referenced data come mostly from the USA and that PMI is asking permission to market IQOS in the USA, our study largely focuses on US data. However, this study can help inform regulation of other HTP products globally, including whether new HTP products should be approved for sale under explicit or implicit reduced risk claims and marketing in light of how reduced-risk claims are perceived by the public.

\section{METHODS}

As part of the public comment process for all FDA MRTP applications submitted from 24 May 242017 to 24 January 2018, the FDA made the majority of PMI's MRTP application materials for HTP available online on a rolling basis. ${ }^{4}$ We analysed the MRTP application materials and researched the available literature to determine whether PMI's claims concerning IQOS could be supported. The following sections of the PMI MRTP application were analysed in whole or in part: (1) Executive Summary; (2) Module 3: Product Description and Formulation; (3) Module 4: Labels, Labeling, and Advertising; (4) Module 6: Summaries of All Research Findings and (5) Module 7: Scientific Studies and Analyses, including product analyses (7.1), preclinical studies (7.2), studies in adult human subjects (7.3), populations health impact model (7.4) and mechanistic and systems toxicology studies. ${ }^{4}$ Considered outside the scope of the present investigation were Module 1 (cover letters), Module 2 (table of contents) and Module 5 (environmental impact), as none contained data germane to the questions addressed in this study.

\section{RESULTS}

Table 1 summarises the evidence required by the Tobacco Control $\mathrm{Act}^{3}$ to make modified risk claims and the evidence provided by PMI in support thereof, including (1) the effect of IQOS marketing on non-users; (2) actual use of the IQOS product and (3) consumer and potential consumer perceptions of IQOS. Table 1 also provides extant evidence on these issues from the literature. For more details on the evidence required and provided by PMI, please see the expanded table in the online supplementary appendix.

PMI's application did not provide any scientific evidence regarding the effect that IQOS and its marketing could have on the likelihood that adolescents who are currently non-tobacco users or who are former tobacco users will start using IQOS (table 1). Instead, PMI claimed that they could not conduct studies on the actual use of IQOS among adolescents, and thereby conducted studies of adults that relied on 'behavioural intention', defined as 'a person's perceived likelihood or subjective probability that he or she will engage in a given behavior,' as a proxy to predict MRTP use behaviours. While many decision-making theories such as Social Cognitive Theory, ${ }^{7}$ the Health Belief Model, ${ }^{8}$ The Theory of Reasoned Action ${ }^{9}$ and The Theory of Planned Behavior ${ }^{9}$ have argued that people's behaviours are largely shaped by their intentions to engage in that behaviour, more recent studies ${ }^{10-13}$ have shown that these models do not accurately or fully predict adolescent behaviour, including tobacco use.

Further, there is concern regarding the packaging of IQOS and its potential impact on AYA use. IQOS packaging resembles iPhones and other high-end smartphones, where the device and parts are neatly placed in moulded plastic trays inside a glossy white box (figure 1). Piper Jaffray's 11 October 2017 'Taking Stock with Teens' survey of 6100 US teens showed that Apple's iPhone continues to rise in popularity among teens, with $78 \%$ of US teens saying they owned an iPhone, and $82 \%$ of teens saying their next smartphone will be an iPhone. ${ }^{14}$ Adding to these concerns, the IQOS flagship stores in Seoul, Korea, visited in June 2017, look remarkably similar to high-end technology brand stores such as Apple or Microsoft stores in the USA (figures 2 and 3). ${ }^{1}$ There is concern that this similarity in appearance to popular personal electronic devices could increase appeal among AYA (the most frequent users of such tech-based devices) and especially since as marketed the IQOS device itself is more similar to a (familiar and low risk) mobile electronic device than a (harmful) tobacco product such as cigarettes. That 

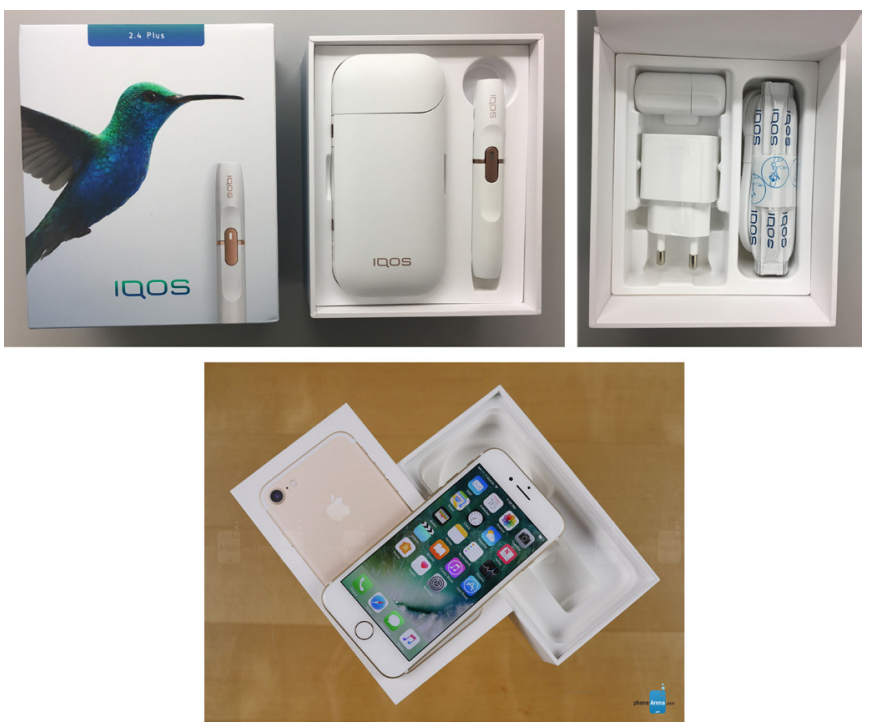

Figure 1 Packaging of IQOS (top: picture taken by Minji Kim) resembles that of a high-end smartphone (bottom: Apple iPhone 7; source: www.phonearena.com).

said, the HeatSticks themselves bear the Marlboro brand and are clearly identifiable as a tobacco product. Packaging and marketing IQOS similarly to non-tobacco products could reduce perceptions of harm. The global experience with e-cigarette marketing demonstrates that perceptions of reduced harm are an important selling point of new products. ${ }^{11} 13$ 15-27 Another

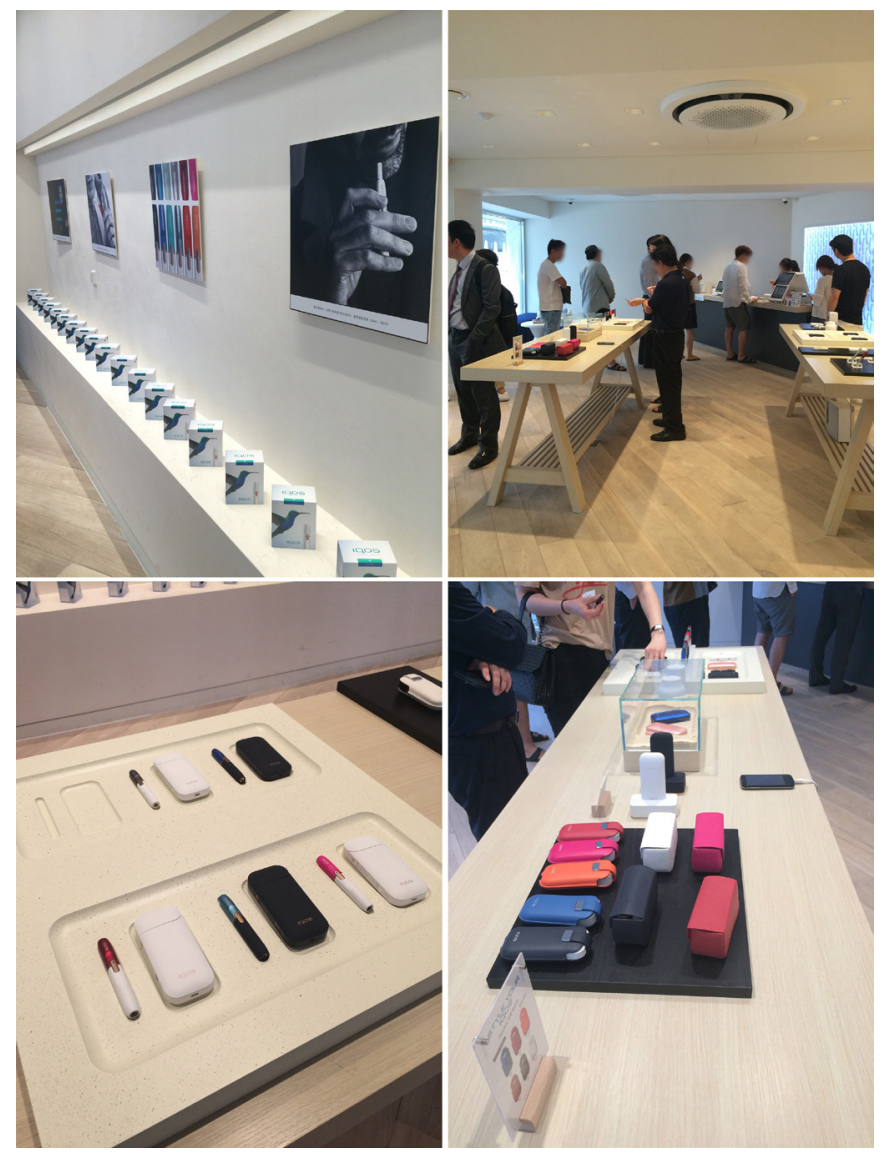

Figure 2 IQOS Flagship store in Seoul, Korea, June 2017 (photos by Minji Kim).

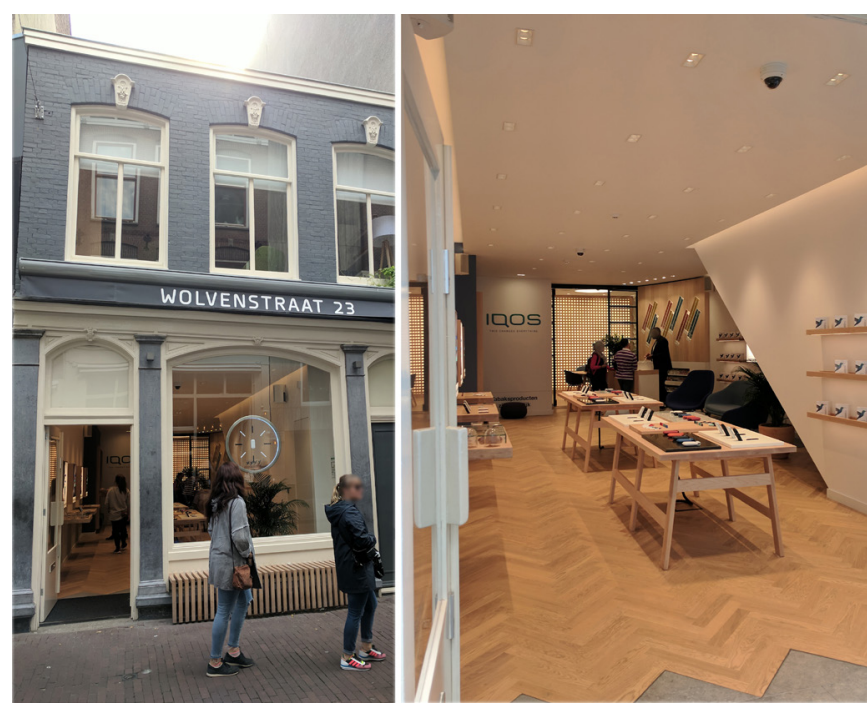

Figure 3 IQOS Flagship store in Amsterdam, Netherlands, September 2017 (photo by Minji Kim).

example is JUUL, a pod-based e-cigarette which looks like a USB stick. $^{28} 29$ The similarity with a popular consumer technology (USB stick) is another reason for JUUL popularity among adolescents, who are able to 'stealth vape' in school without teachers noticing. ${ }^{30-32}$

PMI also did not demonstrate that IQOS, as actually used by consumers, would 'benefit the health of the population as a whole, taking into account both users of tobacco products and persons who do not currently use tobacco products,' of whom AYA are a major group (table 1). For example, it is widely established that AYA are most likely to use flavoured tobacco products, as we have seen with e-cigarettes, little cigars, smokeless tobacco, and hookah. ${ }^{19} 22{ }^{33-41}$ IQOS HeatSticks currently come in three flavours, Marlboro HeatSticks, Marlboro Smooth Menthol HeatSticks and Marlboro Fresh Menthol HeatSticks. PMI was negligent in their review of the existing literature which shows that exposure to flavour-focused tobacco marketing and reduced risk claims attract AYA never-smokers to initiate tobacco use. $^{19} 22$ 33-42 While PMI's application is silent on whether or not there will be more flavours of IQOS in the future, tobacco companies have considerable and well-documented experience developing and using flavours to increase the appeal of cigarettes, e-cigarettes, cigars, and smokeless tobacco to young people. $^{394143-47}$ Given this history, ${ }^{39} 4143-47$ knowing that the flavoured and menthol products appeal to AYA $<<$ PLEASE ADD REFS 19, 22, 33-41 HERE > >, it is highly likely that PMI will apply this expertise to IQOS $<<$ PLEASE DELETE THESE REFS HERE $>>$. 1113 15-27 33 35-42 48

Finally, PMI did not provide sufficient evidence concerning perceptions of HTP products, including potential adolescent, young adult and adult consumers' beliefs about the MRTP claims, health risks, and cessation claims. There is an extensive literature showing that whether or not there is evidence of a product (most notably e-cigarettes) being safer than combustible cigarettes, if adolescents believe a product is safer (i.e., in the absence of clear evidence and consistent warnings), they are more likely to try and use the product which is an undesired population-level outcome (table 1). ${ }^{1518} 2549<<$ PLEASE ALSO ADD REF 48 TO THIS LIST $>>$ For example, many e-cigarette users (including AYA who have not smoked conventional cigarettes and those who are at low risk of smoking cigarettes) started using e-cigarettes 
because they perceived them as less harmful (i.e., 'reduced risk') compared with cigarettes. ${ }^{151618214950}$ This could be explained, at least in part, by how e-cigarettes were marketed online. ${ }^{2651}$ Websites that compared cigarettes with e-cigarettes stated that e-cigarettes were cleaner (95\% of the websites), cheaper ( $93 \%$ of the websites), could be used to circumvent indoor clear air policies ( $71 \%$ of the websites), and could aid in smoking cessation (64\% of the websites). ${ }^{52}$ These data suggest that marketing strategies for IQOS that could reduce perceptions of harm are likely to increase appeal to AYA. In fact, PMI in their 'IQOS Brand Voice Guidelines' is already marketing HTP as cleaner than cigarettes and states as an 'upside' to using their product: 'It produces less of a smell and no ash, so it's less invasive'. In Japan and Switzerland, the marketing was focused more on cleanliness and 'Clinical purity,' rather than direct claims on health benefits or reduced health risks. ${ }^{53}$ In Canada, ${ }^{54}$ PMI is promoting IQOS on their own cigarette packs saying 'Why burn tobacco when you can heat it? Real tobacco. Free of Smoke \& Ash.'

\section{DISCUSSION}

PMI's application to the FDA to market IQOS as a MRTP in the USA ignores the likely effects IQOS and its marketing may have on AYA. PMI fails to provide a sufficiently comprehensive view of how marketing IQOS would benefit the health of the population as a whole and would significantly reduce harm and the risk of tobacco-related disease. PMI failed to provide adequate evidence concerning the effect that IQOS and its marketing will have on the likelihood that non-users (including never users and former tobacco products users) will start using the product bearing the proposed marketing claims. There are several problems with the evidence that was presented in PMI's application.

\section{Behavioural intentions are a poor proxy for actual tobacco use behaviour among AYA}

PMI used behavioural intentions as a proxy to predict MRTP use behaviours, claiming that the effect of IQOS on initiation among non-users could not be assessed in a premarket setting. However, the literature clearly shows that intentions are a poor proxy for actual behaviour, especially among adolescents. ${ }^{8-125556}$ While adolescents may not have an active plan or intention to use tobacco, they often find themselves in situations in which they would consider using even though they were originally committed to avoiding tobacco. Such willingness to use tobacco is a much better predictor of tobacco use than intentions and should be used in studies examining whether and why an adolescent would use any tobacco product. ${ }^{1255}{ }^{57}$ Hence, not only is it incorrect to claim the impact of marketing cannot be assessed, especially considering PMI is already engaged in marketing IQOS around the world, ${ }^{158}$ it is also incorrect to assume intentions are the primary drivers of behaviour, especially for adolescents.

\section{Existing independent research studies on other tobacco products should have been presented}

Companies are expected to provide evidence of population-level harms and benefits that could result from their MRTP application being reviewed by the FDA. Because those under age 18 are part of the population (and usually their initiation of the product results from actions requested in applications such as the instant MRTP application by PMI) and would be affected by population-level harms, the FDA unquestionably needs information on how those under 18 could be affected by any action resulting from an MRTP application.
Still, PMI cited no studies conducted among adolescents younger than 18 , effectively ignoring the fact that most tobacco product use begins before age $18 .^{50}$ There is no reason to expect that initiating IQOS would be any different, particularly in light of the fact that levels of other tobacco product use, including e-cigarettes, are highest among AYA. ${ }^{42} 59-63$ While neither PMI nor any other tobacco company should be permitted to conduct research on youth below the legal age for tobacco use (21 to be conservative) because the companies could use the information to design marketing campaigns to attract them to their products, it is not credible for PMI to argue that it does not know about or has not reviewed the literature on adolescents' use of other tobacco products, including e-cigarettes. Instead, PMI could conduct and present findings from a comprehensive literature review to inform their conclusions. There is a rich evidence-base of studies conducted among adolescents, independent of the tobacco industry, that PMI failed to review, including data on current, former and non-users of cigarettes ${ }^{11} 13$ 15-18 21-27 33-42 57 that will help us understand adolescents' intentions and willingness to use novel, non-cigarette tobacco products analogous to IQOS.

\section{Appeal to adolescents of devices with flavours and high-tech look should have been addressed}

Adolescents' decisions to adopt use of any tobacco product are based on several considerations, including whether the product appeals to them; the product's flavour, smell and taste; the product's perceived harm or reduced harm; and the ease and location of use. ${ }^{15} 1618252964-66$ Just as e-cigarettes, particularly the JUUL-style, promoted with a modern, high-tech image and harm reduction and 'smokeless' messages, appeal to adolescents, it is likely that IQOS, marketed in a similar manner, will also appeal to adolescents. It is especially concerning that the IQOS packaging and retail stores as shown in figures 1-3 closely mimic Apple's iPhone and other savvy, high-tech electronic products which might increase appeal to AYA never-smokers.

Flavour or 'taste' is one of the most commonly used marketing techniques to entice AYA to use a product. ${ }^{67}$ In particular, sweet and salty flavours are used to promote food (mostly candy and snacks) to children and exposure to flavoured products and ads for such products is positively associated with AYA consumption. ${ }^{4068} 69$ Research on other products such as cigars ${ }^{70}{ }^{71} \mathrm{e}$-cigarettes, ${ }^{163438}$ smokeless tobacco ${ }^{5072}$ and waterpipe ${ }^{73} 7_{4}$ comports with these findings. ${ }^{36}{ }^{68}{ }^{70}$ Flavours are frequently used in online e-cigarette marketing and boost user interaction and positive emotion. ${ }^{23} 75$ Further, compared with ads for unflavoured tobacco products, flavoured e-cigarette advertisements elicit greater appeal and interest in buying and trying e-cigarettes. ${ }^{40}$ The appeal of ads for flavours has been linked to rapid and persistent adoption of e-cigarettes among AYA; and $75 \%$ of US AYA stated they would not use e-cigarettes without flavours. ${ }^{76}$ Questions regarding the appeal of IQOS flavours to AYA who have never used a tobacco product were left unanswered in PMI's MRTP application.

\section{Concept of 'switching completely' poorly understood}

PMI's proposed marketing claims are contingent on the phrase 'switching completely from cigarettes to IQOS' which is incongruent with PMI's own evidence regarding how consumers will actually use IQOS, as well as existing epidemiological evidence for related products. Epidemiological evidence suggests that for other non-cigarette tobacco products, switching completely has been an uncommon occurrence. Among US adults who use 
e-cigarettes, $75 \%-82 \%$ use it in combination with at least one other form of combustible tobacco. ${ }^{48} 77$ Similarly, AYA smokers who use novel tobacco products often use two or more kinds of tobacco products concurrently. ${ }^{42} 6378-82$

\section{Evidence of AYA understanding and perceptions should have been presented}

PMI failed to provide evidence concerning AYA understanding and perceptions of HTP products, including labelling, marketing, advertising, MRTP claims, health risks, and cessation. Tobacco use studies among AYA show perceptions that e-cigarettes present less risk than cigarettes predicts e-cigarette use, even among non-smokers. ${ }^{15-183442} 6083-93$ Adolescents report believing that e-cigarettes are safer than cigarettes, can help people quit smoking conventional cigarettes and contain no or just limited amounts of nicotine. ${ }^{15-18} 34426083-93$ Adolescents also consider e-cigarettes to be trendier, more prevalent and more acceptable than conventional cigarettes. ${ }^{15-18} 34426083-93<<$ PLEASE JUST INCLUDE REFS 15-18 HERE; DELETE THE OTHERS FOR THIS LIST ONLUY >> The lowest perceptions of harm and the most positive attitudes regarding e-cigarettes have been reported among adolescents who have used e-cigarettes. ${ }^{10} 162564889495$ Given the similarities between IQOS and e-cigarettes, including the newer JUUL-style (electronic, hi-tech and claims of reduced harm, a better alternative to cigarettes, no 'smoke'), it is reasonable to hypothesise that IQOS will be popular among AYA because they will make similar assumptions about the risks associated with IQOS, and will be willing to initiate and use IQOS. Perceptions of IQOS and e-cigarettes might be very different due to the differences in products; however, at least from risk perception perspective, IQOS studies themselves show similar levels of perceived risk for e-cigarettes and HTP.

Finally, with any reduced risk claims made by the tobacco industry, it is important to consider whether the evidence is from independent studies, versus studies conducted by the industry or influenced or paid for by that industry. Independent studies, as well as an accurate assessment of the extant literature, will better inform whether HTP products will influence tobacco use and misperceptions, with the ultimate goal of improving public health.

\section{LIMITATIONS}

In the absence of a research base for IQOS in the USA, we relied on analogous data from e-cigarette research. While an imperfect analogy, we feel the global regulatory atmosphere that largely treats HTP and e-cigarettes similarly, the parallels in devices such that both HTP and e-cigarettes heat and aerosolise tobacco or tobacco components and/or flavours for inhalation by the user, and the similar marketing techniques for HTP and e-cigarettes allow for reasonable analogies to be made and conclusions to be reached.

\section{CONCLUSION}

When evaluating whether IQOS or any HTP or new tobacco product should be allowed to come to market, one must consider that adolescents who otherwise would not have used any tobacco product might find the new product appealing, and thus likely will initiate tobacco use with this tobacco product. This is especially likely given AYA's attraction to flavoured tobacco products, the appeal of novel and technology-centric products among adolescents and the tendency for the public at large, including AYA, to misinterpret reduced harm claims. PMI completely ignored all the evidence that flavoured products attract AYA and that they will find the IQOS flavours appealing and therefore will be more likely to use them. The tobacco industry could and should use data available from experiences with other tobacco products, such as with e-cigarettes, that have been collected completely independently of the tobacco industry, to draw reasonable inferences about how the HTP product would affect AYA. No regulatory authority throughout the world should allow any new tobacco product to come to market without solid, independent evidence clearly showing that the new product will not appeal to AYA, misinform AYA about risks or encourage use of multiple tobacco products. Failing to account for these effects make it possible that the overall population impact of introducing new HTP (and other new tobacco products) would be negative even if they pose lower individual risks compared with smoking a cigarette.

\section{What this paper adds}

This is the first independent analysis examining whether Philip Morris International's (PMI) proposed marketing of their new IQOS heated tobacco products (HTP) in the USA will appeal to adolescents.

- PMI's own studies failed to provide evidence that reduced risk perception among youth will not lead to increased use of these products.

- PMI did not refer to an important body of existing, independent research that could influence their conclusions.

- Based on PMI's research and evidence from other noncigarette tobacco products (e.g., e-cigarettes), HTPs should not be labelled or sold as a modified-risk tobacco product.

Contributors All authors contributed to the literature review, analyses and writing of the paper.

Funding This work was supported by the US National Cancer Institute and Food and Drug Administration Center for Tobacco Products (P50 CA180890, R00 (A187460) and the National Institute of Drug Abuse and Food and Drug Administration Center for Tobacco Products (P50 DA036128).

Disclaimer The content is solely the responsibility of the author and does not necessarily represent the official views of the National Institutes of Health or the FDA. The funding agencies played no role in design and conduct of the study; collection, management, analysis and interpretation of the data; preparation, review or approval of the manuscript; or decision to submit the manuscript for publication.

Competing interests None declared.

Patient consent Not required.

Provenance and peer review Not commissioned; externally peer reviewed.

Open access This is an open access article distributed in accordance with the Creative Commons Attribution Non Commercial (CC BY-NC 4.0) license, which permits others to distribute, remix, adapt, build upon this work non-commercially, and license their derivative works on different terms, provided the original work is properly cited, appropriate credit is given, any changes made indicated, and the use is non-commercial. See: http://creativecommons.org/licenses/by-nc/4.0/.

\section{REFERENCES}

1 Kim M. Philip Morris International introduces new heat-not-burn product, IQOS, in South Korea. Tob Control 2018;27:e76-e78.

2 International PM, 2017. Our tobacco heating system iqos: tobacco meets technology https://www.pmi.com/smoke-free-products/iqos-our-tobacco-heating-system.

3 US food \& drug administratoion. Family Smoking Prevention and Tobacco Control Act An Overview.

4 Philip Morris SA, 2016. Philip Morris Products SA. Modified Risk Tobacco Product (Mrtp) Applications https://www.fda.gov/downloads/TobaccoProducts/Labeling/Mark etingandAdvertising/UCM560044.pdf.

5 Tabuchi T, Gallus S, Shinozaki T, et al. Heat-not-burn tobacco product use in Japan: its prevalence, predictors and perceived symptoms from exposure to secondhand heatnot-burn tobacco aerosol. Tob Control 2018;27:e25-e33.

6 Liu X, Lugo A, Spizzichino L, et al. Heat-not-burn tobacco products: concerns from the Italian experience. Tob Control 2018:tobaccocontrol-2017-054054. 
7 Bandura A. Social cognitive theory and exercise of control over HIV Infection. Preventing AIDS 1994:25-59.

8 Fishbein M, Belief Al. attitude, intention and behavior: An introduction to theory and research. Reading, MA: Addison-Welsey Publishing Co, 1975.

9 Ajzen I. From intentions to actions: A theory of planned behavior. Action control: Springer 1985:11-39.

10 Halpern-Felsher BL, Biehl M, Kropp RY, et al. Perceived risks and benefits of smoking: differences among adolescents with different smoking experiences and intentions. Prev Med 2004;39:559-67.

11 Gerrard M, Gibbons FX, Benthin AC, et al. A longitudinal study of the reciprocal nature of risk behaviors and cognitions in adolescents: what you do shapes what you think, and vice versa. Health Psychol 1996:15:344-54.

12 Gerrard M, Gibbons FX, Houlihan AE, et al. A dual-process approach to health risk decision making: The prototype willingness model. Developmental Review 2008;28:29-61.

13 McKelvey K, Popova L, Pepper J, et al. Adolescents have unfavorable opinions of adolescents who use e-cigarettes. In review.

14 Jaffray P. Taking Stock with Teens - Fall, 2017.

15 Gorukanti A, Delucchi K, Ling P, et al. Adolescents' attitudes towards e-cigarette ingredients, safety, addictive properties, social norms, and regulation. Prev Med 2017:94:65-71.

16 Kong G, Morean ME, Cavallo DA, et al. Reasons for electronic cigarette experimentation and discontinuation among adolescents and young adults. Nicotine Tob Res 2015; 17:847-54.

17 Maloney EK, Cappella JN. Does vaping in e-cigarette advertisements affect tobacco smoking urge, intentions, and perceptions in daily, intermittent, and former smokers? Health Commun 2016;31:129-38.

18 Roditis M, Delucchi K, Cash D, et al. Adolescents' perceptions of health risks, social risks, and benefits differ across tobacco products. J Adolesc Health 2016;58:558-66.

19 Pepper J, Ribisl K, Brewer N. Adolescents' interest in trying flavoured e-cigarettes, 2016.

20 Institute of Medicine. Committee on Scientific Standards for Studies on Modified Risk Tobacco Products. Scientific Standards for Studies on Modified Risk Tobacco Products: National Academies Press, 2012

21 Kim M, Popova L, Halpern-Felsher B, et al. Effects of e-cigarette advertisements on adolescents' perceptions of cigarettes. Health Commun 2017;2:1-8.

22 McKelvey K, Ramos M, Roditis M, et al. A Qualitative analysis of adolescents' appeal of various tobacco products. In preparation.

23 Pokhrel P, Herzog TA, Muranaka N, et al. Young adult e-cigarette users' reasons for liking and not liking e-cigarettes: A qualitative study. Psychol Health 2015;30:1450-69.

24 Popova L, Ling PM. Perceptions of relative risk of snus and cigarettes among US smokers. Am J Public Health 2013;103:e21-e23.

25 Roditis ML, Halpern-Felsher B. Adolescents' perceptions of risks and benefits of conventional cigarettes, e-cigarettes, and marijuana: a qualitative analysis. J Adolesc Health 2015;57:179-85.

26 Mantey DS, Cooper MR, Clendennen SL, et al. E-cigarette marketing exposure is associated with e-cigarette use among us youth. J Adolesc Health 2016;58:686-90.

27 Pepper JK, Emery SL, Ribisl KM, et al. How risky is it to use e-cigarettes? Smokers beliefs about their health risks from using novel and traditional tobacco products. J Behav Med 2015;38:318-26.

28 Huang J, Duan Z, Kwok J, et al. Vaping versus JUULing: how the extraordinary growth and marketing of JUUL transformed the US retail e-cigarette market. Tob Control 2018:tobaccocontrol-2018-054382.

29 Willett JG, Bennett M, Hair EC, et al. Recognition, use and perceptions of JUUL among youth and young adults. Tob Control 2018:tobaccocontrol-2018-054273.

30 Tucker J. As juul vaping surges among teens, health concerns grow: San Francisco Chronicle Website Published, 2018. https://www.sfchronicle.com/bayarea/article/AsJuul-vaping-surges-among-teens-health-12946713.php.

31 Tolentino J. The promise of vaping and the rise of JUUL. The New Yorker. New York, NY, 2018.

32 Juul BJ, 2018. the vape device teens are getting hooked on, explained https://www. vox.com/science-and-health/2018/5/1/17286638/juul-vaping-e-cigarette (accessed 18 Jun 2016)

33 McMillen RC, Gottlieb MA, Shaefer RM, et al. Trends in electronic cigarette use among u.s. adults: use is increasing in both smokers and nonsmokers. Nicotine Tob Res 2015; 17:1195-202.

34 Wagoner KG, Cornacchione J, Wiseman KD, et al. E-cigarettes, hookah pens and vapes: adolescent and young adult perceptions of electronic nicotine delivery systems. Nicotine Tob Res 2016;18:2006-12.

35 Family Smoking Prevention And Tobacco Control Act, 2012.

36 Feirman SP, Lock D, Cohen JE, et al. Flavored tobacco products in the united states: a systematic review assessing use and attitudes. Nicotine Tob Res 2016;18:739-49.

37 Brown JE, Luo W, Isabelle LM, et al. Candy flavorings in tobacco. N Engl J Med 2014;370:2250-2.

38 Ambrose BK, Day HR, Rostron B, et al. Flavored tobacco product use among us youth aged 12-17 years, 2013-2014. JAMA 2015;314:1871-3.
39 Durkin SJ, Bayly M, Wakefield MA. Can e-cigarette ads undermine former smokers? an experimental study. Tob Regul Sci 2016;2:263-77.

40 Vasiljevic M, Petrescu DC, Marteau TM. Impact of advertisements promoting candy-like flavoured e-cigarettes on appeal of tobacco smoking among children: an experimental study. Tob Control 2016;25(e2):e107-e112.

41 Sterling KL, Fryer CS, Nix M, et al. Appeal and impact of characterizing flavors on young adult small cigar use. Tob Regul Sci 2015;1:42-53.

42 Gilreath TD, Leventhal A, Barrington-Trimis JL, et al. Patterns of alternative tobacco product use: emergence of hookah and e-cigarettes as preferred products amongst youth. J Adolesc Health 2016;58:181-5.

43 Carpenter CM, Wayne GF, Pauly JL, et al. New cigarette brands with flavors that appeal to youth: tobacco marketing strategies. Health Aff 2005;24:1601-10.

44 Kostygina G, Ling PM. Tobacco industry use of flavourings to promote smokeless tobacco products. Tob Control 2016;25:ii40-ii49.

45 Lewis MJ, Wackowski O. Dealing with an innovative industry: a look at flavored cigarettes promoted by mainstream brands. Am J Public Health 2006;96:244-51.

46 Mejia AB, Ling PM. Tobacco industry consumer research on smokeless tobacco users and product development. Am J Public Health 2010;100:78-87.

47 Mejia AB, Ling PM, Glantz SA. Quantifying the effects of promoting smokeless tobacco as a harm reduction strategy in the USA. Tob Control 2010;19:297-305.

48 Kasza KA, Ambrose BK, Conway KP, et al. Tobacco-product use by adults and youths in the United States in 2013 and 2014. N Engl J Med 2017;376:342-53.

49 Roditis M, Lee J, Halpern-Felsher BL, Adolescent H-FBL. Adolescent (mis)perceptions about nicotine addiction: results from a mixed-methods study. Health Educ Behav 2016:43:156-64

50 US Department of Health and Human Services. E-Cigarette use among youth and young adults. A report of the Surgeon General. Atlanta, GA: US Department of Health and Human Services, Centers for Disease Control and Prevention, National Center for Chronic Disease Prevention and Health Promotion, Office on Smoking and Health, 2016.

51 Nicksic NE, Harrell MB, Pérez A, et al. Recall of E-cigarette Advertisements and Adolescent E-cigarette Use. Tob Regul Sci 2017:3:210-21.

52 Grana RA, Ling PM. "Smoking revolution": a content analysis of electronic cigarette retail websites. Am J Prev Med 2014;46:395-403.

53 Hair EC, Bennett M, Sheen E, et al. Examining perceptions about IQOS heated tobacco product: consumer studies in Japan and Switzerland. Tob Control 2018:27(Suppl1):s70-s73.

54 Moodie C, Hammond D, Bauld L. Philip Morris International: a New Year's resolution. Tob Control 2018:27:e79-e80.

55 Gerrard M, Gibbons FX, Stock ML, et al. Images of smokers and willingness to smoke among African American pre-adolescents: an application of the prototype/willingness model of adolescent health risk behavior to smoking initiation. J Pediatr Psychol 2005:30:305-18.

56 Song AV, Morrell HE, Cornell $\mathrm{J}$, et al. Perceptions of smoking-related risks and benefits as predictors of adolescent smoking initiation. Am J Public Health 2009:99:487-92.

57 Wills TA, Sargent JD, Knight R, et al. E-cigarette use and willingness to smoke: a sample of adolescent non-smokers. Tob Control 2016;25(e1):e52-e59.

58 Kiyohara K, Tabuchi T. Electronic cigarette use in restaurants and workplaces where combustible tobacco smoking is not allowed: an Internet survey in Japan. TobControl 2018;27.

59 Barnett TE, Soule EK, Forrest JR, et al. Adolescent electronic cigarette use: associations with conventional cigarette and hookah smoking. Am J Prev Med 2015;49:199-206.

60 Barrington-Trimis JL, Urman R, Leventhal AM, et al. E-cigarettes, cigarettes, and the prevalence of adolescent tobacco use. Pediatrics 2016;138:e20153983.

61 Schoenborn CA, Clarke TC. QuickStats: percentage of adults who ever used an e-cigarette and percentage who currently use e-cigarettes, by age group-national health interview survey, United States. 2017;66:1238-.

62 Centers for Disease Control and Prevention. National Youth Tobacco Survey (NYTS). Web 2016. 2015.

63 Jamal A, Gentzke A, Hu SS, et al. Tobacco use among middle and high school students - United States, 2011-2016. MMWR Morb Mortal Wkly Rep 2017;66:597-603.

64 Ambrose BK, Rostron BL, Johnson SE, et al. Perceptions of the relative harm of cigarettes and e-cigarettes among U.S. youth. Am J Prev Med 2014;47:S53-S60.

65 Cho J, Ching GS, Luong T-H. Impulse buying behavior of Vietnamese consumers in supermarket setting. International Journal of Research Studies in Management 2014;3:33-50

66 Fairchild AL, Bayer R, Colgrove J. The renormalization of smoking? E-cigarettes and the tobacco "endgame". N Engl J Med 2014;370:293-5.

67 Jenkin G, Madhvani N, Signal L, et al. A systematic review of persuasive marketing techniques to promote food to children on television. Obes Rev 2014;15:281-93.

68 Cairns G, Angus K, Hastings G, et al. Systematic reviews of the evidence on the nature, extent and effects of food marketing to children. A retrospective summary. Appetite 2013:62:209-15

69 Kraak VI GJA, McGinnis JM. Food marketing to children and youth: threat or opportunity? National Academies Press, 2006.

70 Hoffman AC, Salgado RV, Dresler C, et al. Flavour preferences in youth versus adults: a review. Tob Control 2016;25:ii32-ii39. 
71 Hinds JT, Li X, Loukas A, et al. Flavored cigars appeal to younger, female, and racial/ ethnic minority college students. Nicotine Tob Res 2018;20:347-54.

72 Ary DV, Lichtenstein E, Severson HH. Smokeless tobacco use among male adolescents: patterns, correlates, predictors, and the use of other drugs. Prev Med 1987; 16:385-401.

73 Smith-Simone S, Maziak W, Ward KD, et al. Waterpipe tobacco smoking: knowledge, attitudes, beliefs, and behavior in two U.S. samples. Nicotine Tob Res 2008;10:393-8

74 Palamar JJ, Zhou S, Sherman S, et al. Hookah use among U.S. high school seniors. Pediatrics 2014;134:227-34.

75 Liang $Y$, Zheng $X$, Zeng DD, et al. Impact of flavor on electronic cigarette marketing in social media. International Conference on Smart Health 2015:278-83.

76 Harrell MB, Weaver SR, Loukas A, et al. Flavored e-cigarette use: Characterizing youth, young adult, and adult users. Prev Med Rep 2017;5:33-40.

77 Weaver SR, Majeed BA, Pechacek TF, et al. Use of electronic nicotine delivery systems and other tobacco products among USA adults, 2014: results from a national survey. Int J Public Health 2016;61:177-88.

78 Haardörfer R, Berg CJ, Lewis M, et al. Polytobacco, marijuana, and alcohol use patterns in college students: A latent class analysis. Addict Behav 2016;59:58-64.

79 Lee YO, Hebert CJ, Nonnemaker JM, et al. Youth tobacco product use in the United States. Pediatrics 2015;135:409-15.

80 Huh J, Leventhal AM. Progression of poly-tobacco product use patterns in adolescents. Am J Prev Med 2016;51:513-7.

81 Ali M, Gray TR, Martinez DJ, et al. Risk profiles of youth single, dual, and poly tobacco users. Nicotine Tob Res 2016;18:1614-21.

82 McKelvey KL, Ramo DE, Delucchi K, et al. Polydrug use among urban adolescent cigarette smokers. Addict Behav 2017:66:145-50.

83 Soneji S, Barrington-Trimis JL, Wills TA, et al. Association between initial use of e-cigarettes and subsequent cigarette smoking among adolescents and young adults: A systematic review and meta-analysis. JAMA Pediatr 2017;171:788-97.

84 Watkins SL, Glantz SA, Chaffee BW. Association of noncigarette tobacco product use with future cigarette smoking among youth in the population assessment of tobacco and health (path) study, 2013-2015. JAMA Pediatr 2018;172:181.
85 Bold KW, Kong G, Camenga DR, et al. Trajectories of e-cigarette and conventional cigarette use among youth. Pediatrics 2018;141:e20171832.

86 Dutra LM, Glantz SA. E-cigarettes and national adolescent cigarette use: 2004-2014. Pediatrics 2017:139:e20162450.

87 Miech RA, O'Malley PM, Johnston LD, et al. E-cigarettes and the drug use patterns of adolescents. Nicotine Tob Res 2016;18:654-9.

88 Anand V, McGinty KL, O'Brien K, et al. E-cigarette use and beliefs among urban public high school students in North Carolina. J Adolesc Health 2015;57:46-51.

89 Lozano P, Barrientos-Gutierrez I, Arillo-Santillan E, et al. A longitudinal study of electronic cigarette use and onset of conventional cigarette smoking and marijuana use among Mexican adolescents. Drug Alcohol Depend 2017:180:427-30.

90 Bold KW, Kong G, Cavallo DA, et al. Reasons for trying e-cigarettes and risk of continued use. Pediatrics 2016;138:e20160895.

91 Choi K, Fabian L, Mottey N, et al. Young adults' favorable perceptions of snus, dissolvable tobacco products, and electronic cigarettes: findings from a focus group study. Am J Public Health 2012;102:2088-93.

92 Hammal F, Finegan BA. Exploring attitudes of children 12-17 years of age toward electronic cigarettes. J Community Health 2016;41:962-8.

93 Leventhal AM, Strong DR, Kirkpatrick MG, et al. Association of electronic cigarette use with initiation of combustible tobacco product smoking in early adolescence. JAMA 2015;314:700-7.

94 Chaffee BW, Gansky SA, Halpern-Felsher B, et al. Conditional risk assessment of adolescents' electronic cigarette perceptions. Am J Health Behav 2015;39:421-32.

95 Trumbo CW, Harper R. Use and perception of electronic cigarettes among college students. J Am Coll Health 2013:61:149-55.

96 Rosenstock IM. Historical origins of the health belief model. Becker M, The Health Belief Model and Personal Health Behavior. Thorofare, NJ: Charles B. Sclack, 1974:1-8.

97 Giovenco DP, Casseus M, Duncan DT, et al. Association between electronic cigarette marketing near schools and e-cigarette use among youth. J Adolesc Health 2016:59:627-34 